\title{
PENGARUH BUDAYA ORGANISASI DAN KOMUNIKASI TERHADAP KINERJA KARYAWAN PT. PARAMITA BANGUN SARANA TBK
}

\author{
Lidia Puspasari \\ STIE Unisadhuguna Jakarta, Indonesia \\ Email : lidia.puspasari@ubs-usg.ac.id
}

\begin{abstract}
Abstrak
Pendahuluan : Keberhasilan untuk mencapai tujuan tergantung kepada efektif dan efisien sumber daya manusia dalam menjalankan tujuan organisasi. Dalam mencapai tujuannya setiap organisasi dipengaruhi oleh perilaku dan sikap orangorang yang terdapat dalam organisasi.

Tujuan : Penelitian ini bertujuan untuk mengetahui efek budaya organisasi dan komunikasi terhadap kinerja karyawan.

Metode : Objek penelitian ini adalah karyawan di PT. Paramita Bangun Sarana Tbk. Jenis penelitian ini menggunakan metode kuantitatif dengan ukuran sampel 67 sampel. Teknik pengambilan sampel menggunakan stratified random sampling yang tidak proporsional. Teknik pengumpulan data yang digunakan adalah studi lapangan, studi literatur, dan kuesioner.

Hasil : Hasil data akan diproses dengan beberapa analisis regresi linear menggunakan aplikasi SPSS versi 20. Hasil analisis penelitian ini menunjukkan bahwa ada pengaruh signifikan terhadap kinerja karyawan dengan hasil R Square sebesar 0,513, yang berarti bahwa kontribusi budaya dan komunikasi organisasi mempengaruhi 51,3\%. Dan hasil penelitian ini menunjukkan bahwa variabel budaya dan komunikasi organisasi memiliki efek yang signifikan sebagian atau bersamaan pada kinerja karyawan.

Kesimpulan : Berdasarkan hasil pengujian dengan menggunakan uji $t$ menunjukkan bahwa secara parsial Komunikasi berpengaruh positif dan signifikan terhadap kinerja karyawan pada PT. Paramita Bangun Sarana Tbk.
\end{abstract}

Kata Kunci : Budaya Organisasi, Komunikasi, Kinerja Karyawan.

\section{Abstract}

Introduction : Success to achieve goals depends on effective and efficient human resources in carrying out organizational goals. In achieving its goals every organization is influenced by the behavior and attitudes of the people in the organization.

Objective : This research aims to determine the effect of organizational culture and communication on employee performance.

Method : The object of this research is an employee at PT. Paramita Bangun Sarana Tbk. This type of research uses quantitative methods with a sample size of 67 samples. Sampling techniques use disproportionate stratified random sampling. The data collection techniques used are field studies, literature studies, and questionnaires.

Results : The data results will be processed with some linear regression analysis using the SPSS application version 20. The results of the analysis of this study showed that there was a significant influence on employee performance with an $R$ Square result of 0.513, meaning that the organization's cultural and 
communication contributions affected 51.3\%. And the results of this study show that organizational culture and communication variables have a partial or concurrently significant effect on employee performance.

Conclusion : Based on the results of testing using the $t$ test shows that partially Communication has a positive and significant effect on employee performance at PT. Paramita Bangun Sarana Tbk.

Keywords : Organizational Culture, Communication, Employee Performance.

\section{Pendahuluan}

Manusia sebagai individu pada dasarnya merupakan makhluk sosial yang memiliki sifat bersosialisasi dan saling membutuhkan dengan individu lainnya (Nuriyah, 2021). Untuk mempermudah dalam bersosialisasi dibutuhkan suatu wadah atau tempat untuk melaksanakannya, untuk itu suatu organisasi sangat diperlukan untuk merealisasikan kegiatan bersosialisasi tersebut (Catio, 2020).

Organisasi pada dasarnya digunakan sebagai tempat atau wadah bagi orang-orang untuk berkumpul, bekerja sama secara rasional dan sistematis, terpimpin dan terkendali, dalam memanfaatkan sumber daya, sarana-prasarana, data dan lain sebagainya yang digunakan secara efektif dan efisien untuk mencapai tujuan organisasi (Kurnia, 2014).

Sumber Daya Manusia adalah sebagai penggerak roda organisasi atau perusahaan (Siregar et al., 2020), jika SDM tidak dikelola dengan baik dan benar maka tidak mungkin organisasi atau perusahaan tersebut dapat berjalan dengan maksimal sesuai dengan yang diharapkan. Maka dari itu sumber daya manusia menjadi asset penting didalam berdirinya suatu organisasi atau perusahaan. Pada dasarnya sumber daya manusia didalam sebuah organisasi berperan penting karena sebagai penggerak dan menentukan pengembangan kegiatan perusahaan. Sehingga sebaik apapun sebuah organisasi, sebanyak apapun sarana dan prasarana yang dimiliki organisasi, tanpa adanya peran dari sumber daya manusia semua tidak akan berjalan dengan baik (Yusuf \& Al Arif, 2015).

Keberhasilan untuk mencapai tujuan tersebut tergantung kepada efektif dan efisien sumber daya manusia dalam menjalankan tujuan organisasi tersebut (Samsuni, 2017). Dalam mencapai tujuannya setiap organisasi dipengaruhi oleh perilaku dan sikap orang-orang yang terdapat dalam organisasi tersebut (Wijaya, 2013). Sifat tersebut dapat menjadi ciri khas bagi seseorang sehingga kita dapat mengetahui sifat seseorang. Sama halnya dengan manusia, organisasi juga memiliki sifat-sifat tertentu yang dapat diketahui berdasarkan karakter organisasi tersebut. Sifat dalam organisasi bisa juga disebut dengan budaya organisasi.

Budaya Organisasi atau Corporate Culture adalah nilai-nilai yang dianut oleh individu berdasarkan pilihan pribadi itu sendiri atau nilai budaya yang sudah lama ada (Pattipawae, 2011). Budaya Organisasi juga memiliki fungsi sebagai gambaran pola atau gaya perilaku individu dalam suatu organisasi. Dan budaya organisasi juga dapat 
digunakan sebagai identitas organisasi atau perusahaan dalam bagaimana mereka melaksanakan kegiatan organisasi (Sutrisno, 2019).

Budaya organisasi yang kuat akan memudahkan tercapainya tujuan-tujuan perusahaan, namun apabila budaya organisasi lemah akan menghambat tercapainya suatu tujuan tersebut. Peran dari seorang pendiri organisasi juga memiliki pengaruh besar terhadap budaya awal organisasi tersebut. Menurut Robins berpendapat bahwa dibutuhkan waktu yang lama untuk pembentukan budaya organisasi. Sekali terbentuk, budaya itu cederung berakar, sehingga sukar bagi para manager untuk mengubahnya (Putri, 2016).

Budaya yang kuat akan mempunyai pengaruh yang besar pada perilaku anggota anggotanya karena tingginya tingkat kebersamaan dan intensitas menciptakan suatu iklim internal dari kendali perilaku yang tinggi (Kokiroba, Areros, \& Sambul, 2021). Budaya organisasi yang kuat akan memudahkan tercapainya tujuan-tujuan perusahaan, namun apabila budaya organisasi lemah akan menghambat tercapainya suatu tujuan tersebut. Peran dari seorang pendiri organisasi juga memiliki pengaruh besar terhadap budaya awal organisasi tersebut (Budiono, 2016).

Dengan adanya budaya organisasi yang terkoordinir diharapkan dapat menumbuhkan rasa kerja sama, hubungan karyawan yang kuat, menciptakan kepercayaan antar karyawan dan terciptanya jalinan komunikasi yang terpadu. Komunikasi yang terpadu dapat memudahkan proses kegiatan organisasi menjadi berjalan dengan baik, karena dengan menjaga interaksi dan komunikasi antar karyawan akan meminimalisirkan hambatan-hambatan penyampaian informasi yang akan terjadi.

Komunikasi adalah suatu kegiatan yang tidak bisa dihindari dalam bersosialisasi antar individu. Pengertian komunikasi itu sendiri adalah suatu proses kegiatan dalam penyampaian, penerimaan dan pengolahan pesan diantara individu atau dua orang atau lebih dengan memiliki tujuan tertentu (Hartati, 2013).

Komunikasi suatu organisasi memberikan pemahaman mengenai peristiwaperistiwa komunikasi yang terjadi di dalamnya, seperti apakah instruksi pimpinan sudah dilaksanakan dengan benar oleh bawahannya ataupun bagaimana bawahannya mencoba menyampaikan keluhan kepada pemimpin selain itu bagaimana komunikasi antar karyawan itu terjadi guna menjalankan kegiatan organisasi.

Didalam sebuah organisasi apabila budaya organisasi dapat terbentuk dengan baik dan terkoordinasi serta komunikasi yang dibangun dengan baik maka akan mempengaruhi suatu kinerja karyawan. Menurut (Mangkunegara, 2011) kinerja karyawan atau job performance adalah hasil kerja secara kualitas dan kuantitas yang dicapai oleh seseorang dalam melaksanakan tugasnya sesuai dengan tanggung jawab yang diberikan kepadanya.

Menurut (Hasibuan \& Hasibuan, 2016) menyatakan bahwa penilaian kinerja adalah aktivitas bagi para manajer untuk mengevaluasi tingkah laku para karyawan yang dilanjutkan dengan menentukan kebijaksanaan kedepannya. Disamping itu tujuan dari penilaian kinerja kerja adalah untuk memperbaiki atau meningkatkan kinerja organisasi atau sebagai evaluasi kinerja dalam organisasi yang nantinya digunakan 
sebagai bahan pertimbangan dalam mengambil langkah-langkah keputusan dimasa depan. Dan dapat dijadikan sebagai alat komunikasi antara pegawai dan pimpinan dalam upaya memperbaiki kinerja organisasi, memastikan bahwa pengambilan keputusan dilakukan secara obyektif dan mengungkapkan permasalahan yang terjadi.

\section{Metode Penelitian}

Metode penelitian ini adalah menggunakan metode pendekatan kuantitatif deskripstif dengan observasi langsung ditempat penelitian (Cresswell, 2017). Teknik pengumpulan data yaitu dengan penyebaran kuesioner sebagai alat pengumpulan data dan hasil data tersebut akan diolah menggunakan aplikasi SPSS versi 20 (Santoso, 2014).

Populasi dalam penelitian ini adalah sebanyak 80 karyawan yang berada dikantor korespondensi dengan jumlah sampel yang digunakan sebanyak 67 sampel berdasarkan perhitungan menggunakan metode solvin. Jenis sampel yang digunakan adalah disproportionate stratified random sampling (Budijanto, 2013).

Untuk menunjang penelitian ini teknik pengumpulan data yang digunakan dalam penelitian ini adalah dengan studi lapangan (Field Research), studi kepustakaan (Library Research) dan penyebaran kuesioner dengan menggunakan skala instrument likert (Sugiyono, 2017).

Setelah data-data yang diperlukan didapat, langkah selanjutnya adalah dengan melakukan uji instrumen. Dalam langkah ini dilakukan dalam 2 (dua) tahap pengujian, yaitu uji validitas dan uji reliabilitas. Untuk menguji validitas kuesioner digunakan rumus korelasi Product Moment Pearson. Sedangkan uji reliabilitas menggunakan alat ukur dengan rumus Alpha Cronbach (Sugiyono, 2016). Dengan Interpretasi koefisien Korelasi r sebagai berikut (Sugiyono, 2017):

Tabel 1

Interpretasi Koefisien Korelasi Nilai $\mathbf{r}$

\begin{tabular}{ll}
\hline Interval Koefisien & Tingkat Hubungan \\
\hline $0,80-1,000$ & Sangat Kuat \\
$0,60-0,799$ & Kuat \\
$0,40-0.599$ & Cukup Kuat \\
$0,20-0,399$ & Rendah \\
$0,00-0,199$ & Sangat Rendah \\
\hline
\end{tabular}

Uji asumsi klasik dalam penelitian ini di lakukan dalam 3 (tiga) pengujian, yaitu: normality test, multicoliinierity test, dan heteroscedasticity test (Arikunto, 2016). Normality test menggunakan metode Kolmogorov smirnov. Multicoliinierity test dilakukan dengan cara menghitung nilai Variance Inflation Factor (VIF) terhadap semua variabel bebasnya. Terjadi multikolinearitas jika nilai VIF > 10,00. Jika nilai VIF $<$ 10,00 korelasi antar variabel bebasnya masih dapat ditolerir (Sugiyono, 2017). Sedangkan uji heteroskedastisitas menggunakan metode Glejser. 
Pengujian berikutnya adalah pengujian parameter, meliputi uji parameter individual (uji statistik t) bertujuan untuk mengukur seberapa jauh pengaruh satu variabel independen secara individual dalam menerangkan variasi variabel dependen dan uji parameter secara simultan. Dan yang terakhir adalah pengujian best of fit model.

\section{Hasil dan Pembahasan}

Penelitian yang menggunakan kuesioner / angket, terlebih dahulu harus dilakukan uji instrumen, yang terdiri dari:

a. Uji Validitas

Hasil uji validitas variabel - variable penelitian dapat dilihat pada Tabel 2 berikut.

Tabel 2

Hasil Uji Validitas Variabel-variabel Penelitian

\begin{tabular}{|c|c|c|c|c|}
\hline Variabel & Pernyataan & $\begin{array}{c}\text { Pearson } \\
\text { Correlation }\end{array}$ & $\mathrm{R}$ tabel & Keterangan \\
\hline \multirow{10}{*}{$\begin{array}{l}\text { Budaya } \\
\text { Organisasi } \\
\text { (X1) }\end{array}$} & BO 1 &, 530 & 0,2369 & Valid \\
\hline & BO 2 & ,467 & 0,2369 & Valid \\
\hline & $\mathrm{BO} 3$ & ,585 & 0,2369 & Valid \\
\hline & $\mathrm{BO} 4$ & ,593 & 0,2369 & Valid \\
\hline & BO 5 & ,534 & 0,2369 & Valid \\
\hline & BO 6 & ,600 & 0,2369 & Valid \\
\hline & BO 7 &, 552 & 0,2369 & Valid \\
\hline & $\mathrm{BO} 8$ &, 515 & 0,2369 & Valid \\
\hline & BO 9 & ,389 & 0,2369 & Valid \\
\hline & BO 10 & ,603 & 0,2369 & Valid \\
\hline \multirow{7}{*}{$\begin{array}{l}\text { Komunikasi } \\
\text { (X2) }\end{array}$} & $\mathrm{K} 1$ & ,530 & 0,2369 & Valid \\
\hline & $\mathrm{K} 2$ & ,475 & 0,2369 & Valid \\
\hline & K3 & ,483 & 0,2369 & Valid \\
\hline & K4 & ,635 & 0,2369 & Valid \\
\hline & K5 & ,535 & 0,2369 & Valid \\
\hline & K6 & ,064 & 0,2369 & Tidak Valid \\
\hline & K7 & ,006 & 0,2369 & Tidak Valid \\
\hline \multirow{10}{*}{$\begin{array}{c}\text { Kinerja } \\
\text { Karyawan } \\
\text { (Y) }\end{array}$} & KK 1 & ,675 & 0,2369 & Valid \\
\hline & KK 2 &, 759 & 0,2369 & Valid \\
\hline & KK 3 & 661 & 0,2369 & Valid \\
\hline & KK 4 & 603 & 0,2369 & Valid \\
\hline & KK 5 & ,760 & 0,2369 & Valid \\
\hline & KK 6 & ,472 & 0,2369 & Valid \\
\hline & KK 7 & ,613 & 0,2369 & Valid \\
\hline & KK 8 & , 475 & 0,2369 & Valid \\
\hline & KK 9 & ,570 & 0,2369 & Valid \\
\hline & KK 10 & ,580 & 0,2369 & Valid \\
\hline
\end{tabular}

Sumber: Data diolah

Untuk mengambil keputusan hasil uji validitas dapat lihat berdasarkan nilai $\mathrm{r}$ hitung $>\mathrm{r}$ tabel maka hasil data tersebut dinyatakan valid. Apabila $\mathrm{r}$ hitung $<\mathrm{r}$ tabel maka dinyatakan hasil data tersebut tidak valid. Hasil dari tabel diatas menunjukkan 
bahwa $\mathrm{r}$ hitung > $\mathrm{r}$ tabel yaitu 0.2369 dengan nilai signifikasi $95 \%$ atau 0.05 maka hasil kuesioner tersebut dinyatakan valid. Indikator yang tidak valid tidak diikutsertakan pada pengujian selanjutnya yaitu uji reliabilitas.

\section{b. Uji Reliabilitas}

Hasil penelitian menunjukan bahwa semua variabel penelitian reliabel. Hal ini ditunjukkan pada Tabel 3 di bawah ini.

Tabel 3

Hasil Uji Reliabilitas Variabel-variabel Penelitian

\begin{tabular}{lcl}
\hline \multicolumn{1}{c}{ Variabel } & Cronbach's Alpha & \multicolumn{1}{c}{ Keterangan } \\
\hline Budaya Organisasi & 0,726 & Reliabel \\
\hline Komunikasi & 0,472 & Cukup Reliabel \\
\hline Kinerja Karyawan & 0,807 & Sangat Reliabel \\
\hline \multicolumn{3}{l}{ Sumber: Data diolah } \\
\end{tabular}

\section{Uji Asumsi Klasik}

Model regresi yang baik, harus memenuhi asumsi BLUE, yaitu Best LinearUnbiased Estimator.

a. Uji Normalitas

Uji normalitas digunakan untuk menguji apakah model regresi mempunyai distribusi normal ataukah tidak. Asumsi normalitas merupakan persyaratan yang sangat penting pada pengujian kebermaknaan (signifikansi) koefisien regresi. Model regresi yang baik adalah model regresi yang memiliki distribusi normal atau mendekati normal, sehingga layak dilakukan pengujian secara statistik.

Uji normalitas dalam penelitian ini menggunakan metode one sample kolmogorov smirnov $(K-S)$ test.

Hasil uji normalitas data penelitian ini dapat dilihat pada Tabel 4 berikut.

Tabel 4

Hasil Uji Normalitas Menggunakan Metode Histogram One-Sample Kolmogorov-Smirnov Test

\begin{tabular}{lcr}
\hline & \multicolumn{2}{c}{$\begin{array}{c}\text { Unstandardized } \\
\text { Residual }\end{array}$} \\
\hline $\mathrm{N}$ & & 67 \\
\hline Normal Parameters $^{\text {a.b }}$ & Mean & $0 \mathrm{E}-7$ \\
\hline & & \\
\hline & Std. Deviation & 3.46960349 \\
\hline Most Extreme Differences & Absolute & .091 \\
\hline & Positive & .091 \\
\hline Kolmogorov-Smirnov Z & Negative & .058 \\
\hline Asymp. Sig. (2-tailed) & & .748 \\
\hline
\end{tabular}

Sumber: Data diolah 
Berdasarkan hasil uji normalitas pada Tabel 4 di atas menunjukkan bahwa nilai signifikan sebesar 0.630 yang berarti lebih besar dari 0.05 maka dapat disimpulkan bahwa variabel di dalam penelitian ini berdistribusi normal.

\section{b. Uji Multikolinearitas}

Uji multikolinearitas bertujuan untuk mengetahui apakah terdapat hubungan yang kuat antar variabel independen. Di dalam penelitian ini uji multikolinearitas menggunakan nilai VIF dan tolerance. Hasil yang didapat disajikan pada Tabel 5 berikut.

Tabel 5

Hasil Uji Multikolinearitas

\begin{tabular}{ccccc}
\hline No & Variabel & Tolerance & VIF & Keterangan \\
\hline 1 & Budaya Organisasi & 0.602 & 1.662 & Bebas multikolinearitas \\
& $\left(\mathrm{X}_{1}\right)$ & & & \\
2 & Komunikasi $\left(\mathrm{X}_{2}\right)$ & 0.602 & 1,662 & Bebas multikolinearitas \\
\hline \multicolumn{5}{c}{ Sumber: Data diolah } \\
\end{tabular}

Berdasarkan Tabel 5 di atas yang menunjukkan nilai tolerance untuk semua variabel independen lebih besar dari 0,1 dan nilai VIF kurang dari 10, maka dapat disimpulkan bahwa variabel independen bebas multikolinearitas.

c. Uji Heterokedastisitas

Heteroskedastisitas adalah varian residual dalam model tidak homogen. Uji untuk mendeteksi adanya gejala heteroskedastisitas dilakukan dengan dengan uji Glejser. Hasil uji heteroskedastisitas dapat dilihat pada Table 6 berikut.

Tabel 6

Hasil Uji Heteroskedastisitas

\begin{tabular}{lcc}
\hline Variabel & Sig. & Kesimpulan \\
\hline $\mathrm{X}_{1} \rightarrow \mathrm{Y}$ & 0,932 & Bebas heteroskedastisitas \\
\hline $\mathrm{X}_{2} \rightarrow \mathrm{Y}$ & 0,052 & Bebas heteroskedastisitas \\
\hline \multicolumn{3}{c}{ Sumber: Data diolah }
\end{tabular}

Dari Tabel 6 di atas terlihat bahwa nilai signifikansi untuk semua variabel independen terhadap dependen lebih besar dari 0,05 , sehingga disimpulkan variabel penelitian bebas dari gejala heteroskedastisitas.

\section{Uji Individual dan Uji Simultan}

Pengujian selanjutnya adalah uji hipotesis. Uji Hipotesis pada penelitian ini dilakukan dalam 2 (dua) pengujian, yaitu:

a. Uji t dan Uji F 
Uji t dilakukan untuk menentukan apakah variable-variabel independen secara parsial berhubungan terhadap variable dependennya. Adapun hasilnya terlihat pada table 8 berikut.

Tabel 7

Hasil Uji t

\begin{tabular}{cccc}
\hline Variabel & $\begin{array}{c}\text { Koefisien } \\
\text { Regresi (B) }\end{array}$ & $\begin{array}{c}\mathbf{t} \\
\text { hitung }\end{array}$ & Sig \\
\hline Budaya Organisasi & 0.488 & 4.044 & 0,000 \\
\hline Komunikasi & 0.638 & 2.993 & 0,004 \\
\hline Fhit $=33.738$ & & 0.000 \\
\hline
\end{tabular}

Sumber: Data diolah

Hasil penelitian menunjukan nilai t hitung pada variabel budaya organisasi sebesar 4.044 dengan nilai sig sebesar 0,00. Kriteria keputusan tolak Ho jika t hitung > t tabel atau sig < taraf kesalahan. Dari hasil penelitian dapat diketahui $\mathrm{t}$ hitung $=4.044$ yang artinya lebih besar dari $\mathrm{t}$ tabel $=2,0281$ atau sig $=0,000<$ taraf kesalahan 5\% maka dapat disimpulkan bahwa budaya organisasi yang digunakan berpengaruh positif terhadap kualitas layanan konsumen. Hal ini ditunjukkan dari nilai koefisien regresi yang dihasilkan bertanda positif yaitu sebesar 0,488.

Hasil penelitian menunjukan bahwa nilai $\mathrm{t}$ hitung variabel komunikasi sebesar 2.993 dengan nilai sig sebesar 0,004. Kriteria keputusan tolak Ho jika t hitung > t tabel atau sig < taraf kesalahan, maka dari hasil penelitian dapat diketahui t hitung $=2.993$ yang lebih besar dari nilai t tabel sebesar 2,081. Maka dapat disimpulkan bahwa budaya organisasi berpengaruh positif terhadap kinerja karyawan PT. Paramita Bangun Sarana Tbk.

Budaya organisasi dan komunikasi secara bersama-sama berpengaruh terhadap kinerja karyawan PT. Paramita Bangun Sarana Tbk. Hal ini dapat dilihat dari nilai $\mathrm{F}$ hitung sebesar 70,737 dengan nilai sig $=0,000$. Sedangkan nilai $\mathrm{F}$ table sebesar 3,505 pada tingkat kesalahan 5\%. Sehingga dapat disimpulkan bahwa terdapat pengaruh secara simultan antara budaya organisasi dan komunikasiterhadap kualitas layanan konsumen.

b. Koefisien Determinasi

Hasil penelitian menunjukan nilai $\mathrm{R}^{2}$ sebesar 0.513 , artinya bahwa variable budaya organisasi dan variable komunikasi secara bersama-sama mampu menjelaskan variabel kinerja karyawan sebesar 51,3\% dan 48,7\% adalah hal lain yang tidak menjadi bagian penelitian ini.

\section{Analisis dan Persamaan Regresi Linear Berganda}

Dari Tabel 8, didapat persamaan regresi linear berganda sebagai berikut:

$$
Y=10.600+0.488 X_{1}+0.638 X_{2}+e
$$

Dimana:

$\mathrm{X}_{1} \quad$ : Budaya organisasi

$\mathrm{X}_{2} \quad$ : Tata Letak Mesin Ordreing 
Y : Kualitas layanan konsumen

Dapat dijelaskan sebagai berikut:

1) Nilai konstanta intersep sebesar 10.600 menyatakan bahwa jika variabel budaya organisasi (X1) dan variabel komunikasi (X2) nol, maka nilai variabel kinerja karyawan (Y) adalah sebesar 10.600.

2) Nilai koefisien regresi variabel budaya organisasi (X1) terhadap variabel kinerja karyawan (Y) adalah sebesar 0.488. Hal ini berarti jika variabel budaya organisasi (X1) naik 1 satuan akan meningkatkan variabel kinerja karyawan (Y) sebesar 0.488, dengan asumsi variabel komunikasi (X2) dan konstanta tetap. Budaya organisasi menurut Cushway dan Lodge adalah sistem nilai yang dianut oleh anggota organisasi yang kemudian mempengaruhi cara mereka dalam bekerja, berperilaku dan beraktivitas. Untuk mengatasi hal tersebut agar hubungan antar karyawan dapat berjalan baik yaitu dengan menanamkan visi dan misi kepada karyawan agar menjalankan setiap tugasnya sesuai dengan arahan dan tujuan perusahaan. Lalu melakukan komunikasi intens contoh mengadakan kegiatan bersama seperti kegiatan training, keagamaan, edukasi, sharing atau gathering. Membangun kepercayaan, menghargai dan saling menghormati antar karyawan. Dan melaksanakan elvaluasi rutin karena kunci sukses sebuah kerja tim adalah evaluasi. Dan evaluasi ini bisa dilihat mana yang sudah berjalan sesuai rencana, mana yang harus mendapatkan perhatian lebih, dan kekurangan apa saja yang harus diperbaiki.

3) Nilai koefisien regresi variabel komunikasi(X2) terhadap variabel kinerja karyawan (Y) adalah sebesar 0.638. Hal ini berarti jika variabel komunikasi(X2) naik 1 satuan akan meningkatkan variabel kinerja karyawan (Y) sebesar 0.638, dengan asumsi variabel budaya organisasi (X1) dianggap konstan.

Menurut Sindu Mulianto komunikasi adalah proses penyampaian pesan oleh pengirim pesan melalui cara dan media tertentu. Interpretasi suatu pesan akan terbentuk dari pola pikir seseorang melalui kebiasaannya, sehingga semakin sama latar budaya antara komunikator dengan komunikan maka komunikasi semakin efektif. Untuk mengatasi agar tidak terjadi kendala di dalam proses komunikasi perusahaan baiknya meninjau kembali bagaimana proses penyampaian informasi tersebut dapat tersebar secara menyeluruh dan dapat tersampaikan kepada karyawan. Dengan membuat atau memperbaruhi sistem informasi tersebut agar semua informasi dapat diakses oleh semua karyawan atau divisi. 


\section{Kesimpulan}

Berdasarkan hasil pengujian dengan menggunakan uji $\mathrm{t}$ menunjukkan bahwa secara parsial budaya organisasi berpengaruh positif dan signifikan terhadap kinerja karyawan pada PT. Paramita Bangun Sarana Tbk. Hal ini dapat dilihat berdasarkan hasil $\mathrm{t}$ hitung $>\mathrm{t}$ tabel yang diperoleh nilai sebesar $4.044>2.262$ dengan nilai signifikan $0.000>0.05$. Berdasarkan hasil pengujian dengan menggunakan uji t menunjukkan bahwa secara parsial Komunikasi berpengaruh positif dan signifikan terhadap kinerja karyawan pada PT. Paramita Bangun Sarana Tbk. Hal ini dapat dilihat berdasarkan hasil $\mathrm{t}$ hitung $>\mathrm{t}$ tabel yang diperoleh dengan nilai sebesar $2.993>2.262$ dengan nilai signifikan $0.004>0.05$. Hasil pengujian menyatakan bahwa pada budaya organisasi dan komunikasi secara bersama-sama mempengaruhi kinerja karyawan PT. Paramita Bangun Sarana Tbk, hal ini dapat dilihat berdasarkan hasil uji F hitung > f tabel yang diperoleh dengan nilai sebesar $33.738>3.13$ dengan nilai signifikan $0.000>0.05$. 


\section{DAFTAR PUSTAKA}

Arikunto, Suharsimi. (2016). Prosedur Penelitian Suatu Pendekatan Praktis. Jakarta: PT Rineka Cipta.

Budijanto, Didik. (2013). Populasi, Sampling, dan Besar Sampel. Kementerian Kesehatan RI.

Budiono, Dewi Suryani. (2016). Pengaruh Budaya Organisasi terhadap Kinerja Karyawan melalui Komitmen Organisasi sebagai Variabel Intervening pada PT. Kerta Rajasa Raya. Jurnal Riset Ekonomi Dan Manajemen, 16(1), 29-43.

Catio, Mukhlis. (2020). Manajemen Sumber Daya Manusia. Indigo Media.

Cresswell, J. W. (2017). Research Design: Pendekatan Kualitatif, Kuantitatif, dan Mixed (Edisi Ketiga). Yogyakarta: Pustaka Belajar.

Hartati, Desi Sri. (2013). Interaksi sosial kelompok lanjut usia sebelum dan sesudah tinggal di Panti Sosial Tresna Wredha Budi Pertiwi di Kelurahan Burangrang Kecamatan Lengkong Kota Bandung. UIN Sunan Gunung Djati Bandung.

Hasibuan, Malayu S. P., \& Hasibuan, H. Malayu S. P. (2016). Manajemen sumber daya manusia. Bumi Aksara.

Kokiroba, Eugene K., Areros, William A., \& Sambul, Sofia A. P. (2021). Pengaruh Budaya Organisasi terhadap Kinerja Karyawan pada PT. Batavia Properindo Finance Tbk. Cabang Manado. Productivity, 2(4), 294-298.

Kurnia, Heri. (2014). Pengaruh Keaktifan Berorganisasi Terhadap Indeks Prestasi Kumulatif Mahasiswa Universitascokroaminoto Yogyakarta. Academy of Education Journal, 5(2).

Mangkunegara, A. A. Anwar Prabu. (2011). Manajemen sumber daya manusia perusahaan.

Nuriyah, Inwanatun. (2021). Kedudukan Manusia.

Pattipawae, Dezonda R. (2011). Penerapan nilai-nilai dasar budaya kerja dan prinsipprinsip organisasi budaya kerja pemerintah dengan baik dan benar. Sasi, 17(3), 3144.

Putri, Asti Septiani. (2016). Pengaruh Disiplin Kerja Dan Budaya Organisasi Terhadap Kinerja Karyawan Di Pt. Kereta Api Indonesia (Persero) Daop Ii Bandung. Fakultas Ekonomi Unpas Bandung.

Samsuni, Samsuni. (2017). Manajemen sumber daya manusia. Al-Falah: Jurnal Ilmiah Keislaman Dan Kemasyarakatan, 17(1), 113-124.

Santoso, Singgih. (2014). Panduan Lengkap SPSS versi 20 edisi revisi. Jakarta: PT. Elex Media Komputindo.

Siregar, Robert Tua, Sahir, Syafrida Hafni, Sisca, Sisca, Candra, Vivi, Wijaya, Andy, Masrul, Masrul, Sianturi, Efendi, Simarmata, Hengki M. P., Revida, Erika, \& Purba, Sukarman. (2020). Manajemen Sumber Daya Manusia Dalam Organisasi. Yayasan Kita Menulis.

Sugiyono. (2017). Metode Penelitian Kuantitatif, Kualitatif, dan R\&D. Bandung: Alfabeta.

Sutrisno, H. Edy. (2019). Budaya organisasi. Prenada Media.

Wijaya, Ida Suryani. (2013). Komunikasi interpersonal dan iklim komunikasi dalam organisasi. Jurnal Dakwah Tabligh, 14(1), 115-126.

Yusuf, Burhanuddin, \& Al Arif, M. Nur Rianto. (2015). Manajemen sumber daya manusia di lembaga keuangan syariah. Rajawali Pers. 